\title{
Effect of the Notch4/DIl4 signaling pathway in early gestational intrauterine infection on lung development
}

\author{
CANYANG ZHAN, YI SUN, JIARONG PAN, LIHUA CHEN and TIANMING YUAN \\ Department of Neonatology, Children's Hospital, School of Medicine, \\ Zhejiang University, Hangzhou, Zhejiang 310003, P.R. China
}

Received May 29, 2020; Accepted February 5, 2021

DOI: $10.3892 /$ etm.2021.10404

\begin{abstract}
Intrauterine infection is an important risk factor for bronchopulmonary dysplasia (BPD). BPD is characterized by arrested lung alveolarization and impaired pulmonary vascularization. The Notch4 signaling pathway is a key regulator of vascular remodeling and angiogenesis. Therefore, the presents study investigated the expression of Notch4, delta-like canonical Notch ligand 4 (Dll4) and related factors in an in vivo rat model and in rat pulmonary microvascular endothelial cells (PMVECs) in vitro, to study the mechanisms by which intrauterine infection affects rat lung development. A rat model of intrauterine infection was established by endocervical inoculation with Escherichia scoli on embryonic day 15. The date of birth was counted as postnatal day 0 (P0). Then, the lung tissues were collected from pups at days P3-P14. The expression of Notch4, Dl14 and related factors was measured by reverse transcription-quantitative PCR and western blotting. In addition, the $\gamma$-secretase inhibitor DAPT was used to examine the effect of Notch4 signaling on PMVECs. Intrauterine E. coli infection impaired normal lung development, as indicated by decreased microvessel density, fewer alveoli, fewer secondary septa, and larger alveoli compared with the control group. Furthermore, Notch4, Dll4 and NF- $\kappa$ B levels were significantly increased in the E. coli-infected group at P3 compared with the control group. Similarly, the mRNA expression levels of fetal liver kinase 1 (Flk-1, a VEGF receptor) were significantly increased in the E. coli-infected group at P3 and P7. In PMVECs, the inhibition of Notch4 signaling contributed to decreases in lipopolysaccharide (LPS)-induced expression of VEGF and its receptors. Furthermore, the inhibition of Notch4/Dll4 signaling accelerated cell proliferation and decreased the apoptosis rate of LPS-induced PMVECs. LPS-induced NF- $\kappa \mathrm{B}$ expression in PMVECs was also attenuated by the Notch4/Dll4 inhibitor. In
\end{abstract}

Correspondence to: Dr Canyang Zhan, Department of Neonatology, Children's Hospital, School of Medicine, Zhejiang University, 3333 Binsheng Road, Hangzhou, Zhejiang 310003, P.R. China E-mail: 6310005@zju.edu.cn

Key words: Notch4, delta-like canonical Notch ligand 4, intrauterine infection, bronchopulmonary dysplasia, VEGF, angiogenesis conclusion, intrauterine $E$. coli infection impaired normal lung development, possibly through Notch4/Dll4 signaling and effects on VEGF and its receptors.

\section{Introduction}

Bronchopulmonary dysplasia (BPD) is one of the most common complications in extremely preterm infants and is associated with many factors, including mechanical ventilation, hyperoxia, genetic predisposition, infections and inflammation (1). New BPD manifests as impaired lung alveolarization and aberrant microvasculature (2). Evidence indicates that angiogenesis is crucial for lung development, while alveolarization impairment due to disrupted angiogenesis is critical to the development of BPD (3-5). A great deal of clinical and animal research has shown that there is a relationship between infection/inflammation and BPD (6-8). BPD was increased in preterm infants who had a history of chorioamnionitis (6). In animal models, intra-amniotic lipopolysaccharide (LPS) administration impaired the growth of alveoli and vessels $(7,8)$. Although increasing evidence shows that intrauterine inflammation can impair alveolarization, the exact mechanism remains unclear, and no effective therapies are currently available to prevent BPD.

Notch signaling is an evolutionarily conserved intercellular signaling mechanism that has a major role in regulating cell fate in mammals and other vertebrates. Notch signaling is activated when Notch ligands bind to Notch receptors that are expressed on the surface of the adjacent cell. In mammals, there are five Notch ligands [jagged canonical Notch ligand (Jag) 1, Jag2, delta-like canonical Notch ligand (D11) 1, D113 and D114] and four Notch receptors (Notch1-4) $(9,10)$. Among these Notch receptors and ligands, Notch4 and its ligand Dll4 are primarily expressed in the vascular endothelium. Notch4 has been reported to be associated with arteriovenous malformations. Notch4 or Dll4 overexpression in the vasculature results in defective embryonic angiogenesis, while Dll4 or Notch receptor deficiency leads to embryonic lethality with profound vascular defects (11). These results suggest that balanced levels of Notch4/D114 signaling are necessary for normal vascular development. However, the role of Notch4/Dll4 signaling during vascular remodeling in BPD has not been well studied.

The current study focused on the expression of Notch4, Dll4 and related factors in vivo, in a rat model, and in vitro, 
in rat pulmonary microvascular endothelial cells (PMVECs), to verify the effect of Notch4/Dl14 signaling in intrauterine infection on lung development.

\section{Materials and methods}

Animal model. Twenty pregnant Sprague-Dawley rats were purchased from the Laboratory Animal Center of Zhejiang Academy of Medicine in China and randomized into two groups: The Escherichia coli-infected group $(\mathrm{n}=10)$ and the control group $(\mathrm{n}=10)$. All animals were housed under standard laboratory conditions at $22 \pm 2^{\circ} \mathrm{C}$ with a constant 12-h light/dark cycle. On embryonic day E15, pregnant rats were anesthetized with $2 \%$ sodium pentobarbital $(40 \mathrm{mg} / \mathrm{kg}$, intraperitoneal injection). Then, $0.4 \mathrm{ml}$ of either an E. coli suspension $\left(2.5-4 \times 10^{8}\right.$ colony-forming units per $\left.\mathrm{ml}\right)$ or saline was injected into the uterine cervix of the rats $(12,13)$. All animal procedures and protocols were reviewed and approved by the Animal Care Committee of Zhejiang University.

All pregnant rats were allowed to give birth naturally. They were checked daily to confirm whether they gave birth, and the day of birth was considered as postnatal day 0 (P0) for the pups. Most of the rats were delivered at 21-22 days. Furthermore, there was no significant difference between the control group and the E. coli-treated group regarding the duration of pregnancy and day of delivery. The period of the human or rat lung development has been divided into five stages: Embryonic stage, pseudoglandular stage, canalicular stage, saccular stage and alveolar stage. BPD is mainly observed at the saccular stage. One pup per litter from each group was sacrificed at P3 (saccular stage), P7 and P14 (alveolar stage). The rats were anesthetized with $2 \%$ sodium pentobarbital ( $40 \mathrm{mg} / \mathrm{kg}$, intraperitoneal injection). These rats were euthanized by exsanguination via excision of the inferior vena cava before the lung tissues were collected. Thus, lung tissue samples from P3 to P14 were harvested in both groups ( $\mathrm{n}=10$ per time point). The right upper lobe was fixed for $24 \mathrm{~h}$ at room temperature in $10 \%$ neutral formaldehyde for histopathological examination. Other specimens were frozen in liquid nitrogen and stored at $-80^{\circ} \mathrm{C}$ for further analysis. Intrauterine infection was confirmed by the presence of inflammation in histological sections of the uterus and placenta, as described in a previous study (12).

Histology and immunohistochemistry. Lung samples were fixed overnight in $10 \%$ formalin at a pressure of $20 \mathrm{~cm} \mathrm{H}_{2} \mathrm{O}$. Then, the tissues were dehydrated in graded ethanol and embedded in paraffin. Sections of $5 \mu \mathrm{m}$ thickness were cut and stained with hematoxylin and eosin (H\&E). Radial alveolar counts (RACs) were measured by drawing a perpendicular line from the respiratory bronchiole to either the pleura or the nearest connective tissue septum, and the number of alveoli transected by this line was counted. Three sections per time point were randomly selected for analysis. Five fields from each section were used to perform morphometric analysis and RACs using a light microscope (magnification, $\mathrm{x} 100$ ).

Furthermore, the sections were used for immunohistochemical (IHC) staining. Briefly, tissue sections were subjected to antigen retrieval using citrate buffer $(\mathrm{pH}=6.0)$. Hydrogen peroxide (3\%) was used for $10 \mathrm{~min}$ at room temperature for blocking of endogenous peroxidases. The sections were then incubated with primary antibodies targeting CD34 (1:2,500; cat. no. ab81289; Abcam) overnight at $4^{\circ} \mathrm{C}$, followed by incubation with secondary antibodies (HRP-conjugated goat anti-rabbit IgG; 1:200; cat. no. ab6721; Abcam) for $1 \mathrm{~h}$ at room temperature. The IHC reaction color was visualized with 3,3 diaminobenzidine (Sigma-Aldrich; Merck KGaA) as the substrate using a light microscope (magnification, $\mathrm{x} 200$ ). Image-Pro Plus version 6.0 software (Media Cybernetics, Inc.) was used for analysis.

Cell culture. Rat PMVECs were obtained from Qingqi (Shanghai) Biotechnology Development Co., Ltd. and were incubated in serum-free DMEM (Invitrogen; Thermo Fisher Scientific, Inc.) for $24 \mathrm{~h}$. PMVECs were pretreated with $10 \mu \mathrm{mol} / \mathrm{l}$ DAPT (cat. no. ab120633; Abcam) or equal volume of vehicle PBS for $24 \mathrm{~h}$ according to previous studies $(14,15)$. Subsequently, the cells were stimulated with or without $10 \mu \mathrm{g} / \mathrm{ml}$ LPS in serum-free DMEM for $48 \mathrm{~h}$, resulting in the following three experimental groups: Control group, PMVECs treated with PBS vehicle control only; LPS group, PMVECs treated with LPS only; and DAPT+LPS group, PMVECs treated with DAPT and LPS (16-18).

MTT assay. Cell proliferation and viability were measured with an MTT assay. Briefly, exponentially growing cells $\left(4 \times 10^{4} /\right.$ well) were seeded in a $96-$ well plate and cultured for $72 \mathrm{~h}$. For each group, the wells were randomly sampled every $24 \mathrm{~h}$, and MTT solution ( $5 \mathrm{mg} / \mathrm{ml}, 20 \mu \mathrm{l} /$ well; Sigma-Aldrich; Merck KGaA) was added to the selected wells. After the wells were incubated for an additional $2 \mathrm{~h}$ at $37^{\circ} \mathrm{C}, 200 \mu \mathrm{l}$ of DMSO was added to the wells, and the cell viabilities were determined by measuring the optical density values at $490 \mathrm{~nm}$ with a microplate reader (ELX-800; BioTek Instruments, Inc.).

Apoptosis assay. The effect of Notch4/Dl14 signaling on PMVEC apoptosis was evaluated by Annexin V staining. PMVECs were collected, washed 3 times with PBS buffer and suspended in binding buffer at a density of $10^{6} \mathrm{cell} / \mathrm{s} / \mathrm{ml}$. Then, the cells were stained with Annexin V-fluorescein isothiocyanate (FITC) and propidium iodide using an Annexin V FITC apoptosis detection kit (JingMei Biotechnology Co., Ltd.), according to the manufacturer's protocol. Apoptotic cells were subsequently analyzed by flow cytometry (LSRFortessa SORP; BD Biosciences) and FlowJo v7.6 software (FlowJo LLC).

$R N A$ preparation and reverse transcription-quantitative PCR. Total RNA was extracted from small pieces of frozen lung tissue or from cells by using a RNeasy Mini kit (Qiagen $\mathrm{GmbH}$ ). The RNA was then reverse transcribed into cDNA using High-Capacity cDNA Reverse Transcription Kit (Invitrogen; Thermo Fisher Scientific, Inc.), which was used for quantitative PCR on an ABI PRISM 7500 Real-Time PCR System (Thermo Fisher Scientific, Inc.) as previously described (12). A SYBR-Green PCR kit (Takara Biotechnology Co., Ltd.) was used for the qPCR analysis using the $2^{-\Delta \Delta \mathrm{Cq}}$ method (19). The primers (Table I) were designed using Primer Express 3.0 software (Applied Biosystems; Thermo Fisher Scientific, Inc.) and synthesized by Takara Biotechnology Co., Ltd. GAPDH was used as an endogenous control gene to normalize the amount 
Table I. Sequences of primers used for reverse transcription-quantitative PCR.

\begin{tabular}{|c|c|c|c|}
\hline Gene & Primer & Sequence $\left(5^{\prime}-3^{\prime}\right)$ & PCR product length (bp) \\
\hline \multirow[t]{2}{*}{ Dl14 } & Forward & AGAGGAGAAGGAGGAGGAATG & 130 \\
\hline & Reverse & CCCTTGACTCTTCСCTTGATG & \\
\hline \multirow[t]{2}{*}{ Notch4 } & Forward & ATTCCCAGTGCTGGCTTCTC & 177 \\
\hline & Reverse & GAGCGTTGTTGCAGCCTTTC & \\
\hline \multirow[t]{2}{*}{$\mathrm{NF}-\kappa \mathrm{B}$} & Forward & AGCTGCTATTGGATTACAC & 109 \\
\hline & Reverse & AGATGGCTAGAAAGAACAC & \\
\hline \multirow[t]{2}{*}{ Flk-1 } & Forward & TTACTGTCCAGCCTGCTAC & 173 \\
\hline & Reverse & CCAAAGAGCGTCCAAGTTC & \\
\hline \multirow[t]{2}{*}{ Flt-1 } & Forward & ATAGCGTGGGACAGTAGG & 164 \\
\hline & Reverse & CTCGGTGGGCTTATTTGG & \\
\hline \multirow[t]{2}{*}{ VEGF } & Forward & GAGTCTGTGCTCTGGGATTTG & 188 \\
\hline & Reverse & TCСТGCTACСТСТTTССТCTG & \\
\hline \multirow[t]{2}{*}{ GAPDH } & Forward & GTCGGTGTGAACGGATTTG & 181 \\
\hline & Reverse & TCCCATTCTCAGCCTTGAC & \\
\hline
\end{tabular}

Dll4, delta-like canonical Notch ligand 4; Flk-1, fetal liver kinase 1; Flt-1, FMS-like tyrosine kinase 1.

of cDNA. The amplification procedure was performed in two steps: Initial denaturation at $95^{\circ} \mathrm{C}$ for $3 \mathrm{~min}$ and 40 cycles of $95^{\circ} \mathrm{C}$ for $15 \mathrm{sec}$ and $60^{\circ} \mathrm{C}$ for $45 \mathrm{sec}$.

Western blot analysis. Total protein was extracted from frozen lung tissue samples (40 mg) or cells using RIPA buffer (Abcam). Equal amounts of protein determined using the BCA method $(50 \mu \mathrm{g})$ were separated by $10 \%$ SDS-PAGE and transferred onto nitrocellulose membranes by electroblotting. Then, the membranes were blocked with 5\% nonfat dried milk for $2 \mathrm{~h}$ at room temperature and incubated with primary antibodies overnight at $4{ }^{\circ} \mathrm{C}$. The following primary antibodies were used: Anti-D114 (1:1,000; cat. no. ab183532; Abcam), anti-Notch4 (1:1,000; cat. no. ab184742; Abcam), anti-VEGF (1:1,000; cat. no. ab72807; Abcam), anti-fetal liver kinase 1 (Flk-1; 1:2,000; cat. no. ab221679; Abcam), anti-FMS-like tyrosine kinase 1 (Flt-1; 1:2,000; cat. no. ab184784; Abcam), anti-NF-кB (1:1,000; cat. no. 8242; Cell Signaling Technology, Inc.) and anti-GAPDH (1:2,000; cat. no. 5174; Cell Signaling Technology, Inc.). The next day, the membranes were washed with TBST (containing $0.05 \%$ Tween 20 in TBS buffer) three times for $10 \mathrm{~min}$, followed by incubation with anti-rabbit (cat. no. ab6721), anti-mouse (cat. no. ab6728) and anti-goat (cat. no. ab6741) HRP-conjugated secondary antibodies (all 1:5,000; all from Abcam) for $2 \mathrm{~h}$ at room temperature. Finally, the proteins were detected by chemiluminescence (ECL Plus Detection kit; Beyotime Institute of Biotechnology). Then, the membranes were exposed to X-ray film to visualize the protein bands. Protein bands were scanned and quantified using a computer-based image analysis system (Gel-Pro analyzer software 4.0; Media Cybernetics, Inc.). GAPDH was used as the endogenous control.

Statistical analysis. All data are presented as the mean \pm standard deviation (SD). A t-test was used to measure the statistical significance of the difference between the means of two groups (E. coli-infected group and control group). The differences among multiple groups of samples (PMVEC treatment groups) were evaluated using analysis of variance with Tukey's post hoc test. Data analyses were performed using the SPSS software package version 18 for Windows (SPSS Inc.). $\mathrm{P}<0.05$ was considered to indicate a statistically significant difference.

\section{Results}

Intrauterine infection impairs lung development. During the present study, no dams died after intrauterine $E$. coli administration. There were few intrauterine fetal deaths and pregnancy losses in the two groups. Ninety-eight live pups from the control group and ninety-four live pups from the E. coli-infected group were eligible for this study (Table II). Compared with that of pups in the control group (Fig. 1A), the lung morphology of the pups in the $E$. coli-infected group displayed fewer alveolar numbers, larger alveoli, fewer secondary septa and thickened alveolar septa (Fig. 1B). Furthermore, a higher microvessel density (CD34 expression in lung tissue) was observed in the control group (Fig. 1C) compared with the E. coli-infected group (Fig. 1D). There was no marked difference in the histological evidence of alveolar structure destruction or fibrosis between the two groups. The RAC, as an important index of lung development, increased gradually from P3 to P14. Notably, the RAC of the control group at P7 and P14 was significantly higher compared with that of the E. coli-infected group (both $\mathrm{P}<0.05$; Fig. 1E).

Notch4, Dll4, NF- $\kappa B, V E G F$, Flt-1 and Flk-1 are aberrantly expressed in the rat lung after intrauterine infection. To investigate whether intrauterine infection altered the expression of Notch4, Dll4, NF- $\kappa$ B, VEGF, Flt-1 (also known as VEGFR1) and Flk-1 (also known as VEGFR2) in the rat lung, PCR and western blot analysis were performed. Compared with those 
Table II. Induction of pregnancy losses by intrauterine infection.

\begin{tabular}{llcc}
\hline Time points & \multicolumn{1}{c}{ Litters/fetuses } & Escherichia coli-treated group (n=10) & Control group (n=10) \\
\hline P3,7,14 & Pregnant rats/fetuses & $10 / 94$ & $10 / 98$ \\
& Stillborn litters & 1 & 0 \\
& Stillborn pups & 5 & 3 \\
\hline
\end{tabular}
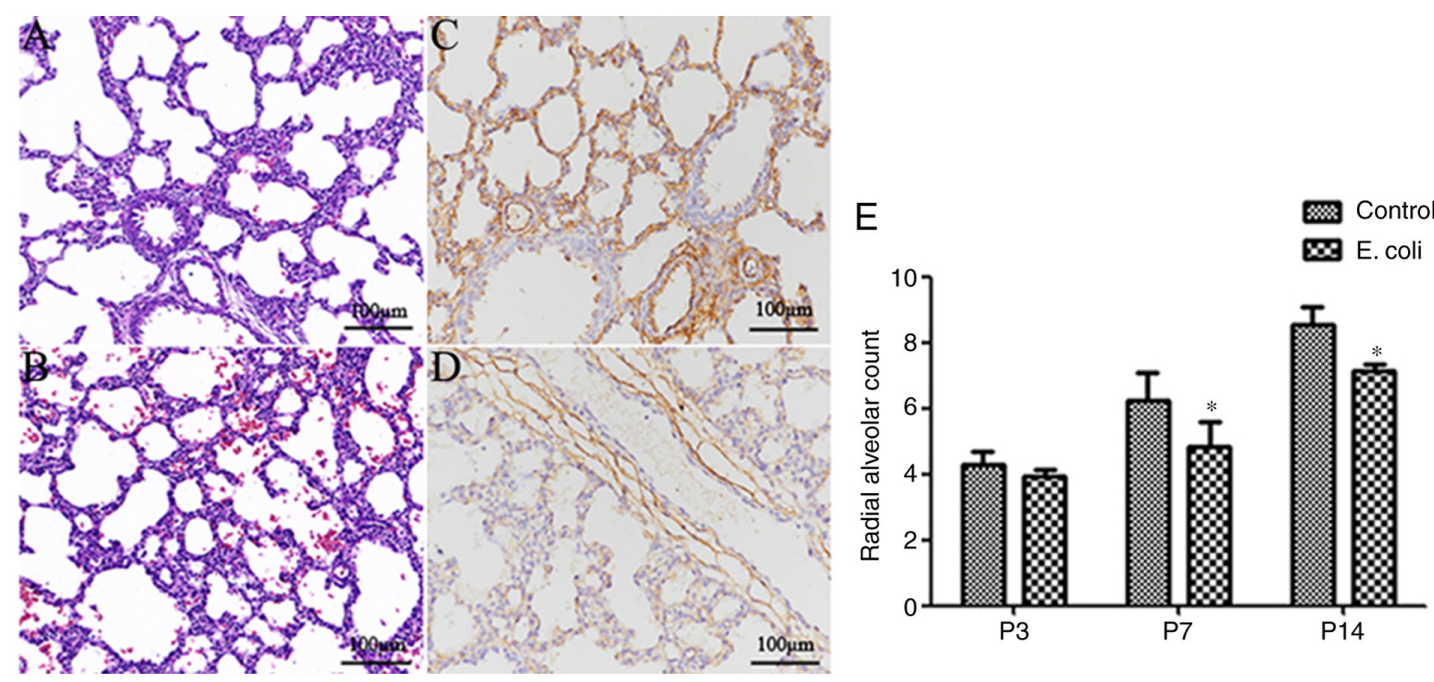

Figure 1. Lung morphology, immunohistochemistry and the radial alveolar counts of both groups. (A) Representative images of H\&E-stained lung sections from control pups at P7 and (B) from E. coli-infected pups at P7. (C) Representative images of CD34 immunohistochemistry staining (a blood vessel marker) of lung tissues from control pups at P7 and (D) from E. coli-infected pups at P7. Magnification, x200. Scale bar, $100 \mu \mathrm{m}$. (E) Radial alveolar counts in the control and E. coli-infected groups on P3, P7, P14. Data are presented as the mean $\pm \mathrm{SD}\left(\mathrm{n}=10\right.$ per group). ${ }^{*} \mathrm{P}<0.05$. $\mathrm{P}$, postnatal day.

of the control group, the mRNA expression levels of Notch4 (Fig. 2A) and Dll4 (Fig. 2B) after intrauterine infection were significantly upregulated at $\mathrm{P} 3(\mathrm{P}<0.05)$. A similar trend in Notch4 and Dll4 protein expression was observed by western blotting (Fig. 2G). However, there was no significant difference in expression between the two groups at the other time points. There was a significant difference in the Flk-1 mRNA expression levels at P3 and P7 between the two groups (both $\mathrm{P}<0.05$; Fig. 2E), while the mRNA expression levels of Flt-1 were significantly increased at P14 compared with those of the control group $(\mathrm{P}<0.05$; Fig. $2 \mathrm{~F})$. Additionally, the results demonstrated that the protein and mRNA expression levels of $\mathrm{NF}-\kappa \mathrm{B}$ were significantly increased in the $E$. coli-infected group at $\mathrm{P} 3$ compared with the control group $(\mathrm{P}<0.05$; Fig. $2 \mathrm{C}$ and $\mathrm{G})$. The protein expression levels of Flk-1 in lung tissues from the $E$. coli-infected group were significantly higher compared with those of the control group at P3 (Fig. 2H); however, there was no difference in VEGF or Flt-1 protein expression levels between the two groups at P3 (Fig. 2H).

LPS induces the expression of Notch4, Dll4, VEGF, Flt-1 and Flk-1 in PMVECs. PMVECs were exposed to different concentrations of LPS to determine the optimal concentration for further experiments. The dose of $10 \mu \mathrm{g} / \mathrm{ml}$ LPS was selected because it induced the greatest mRNA upregulation of Notch4 and Dll4 (Fig. 3A). Subsequently, RT-qPCR analysis revealed that the mRNA expression levels of Notch4 and Dll4 in the LPS-treated PMVEC group were significantly increased compared with those of control cells (both $\mathrm{P}<0.05$; Fig. 3B and C). The Notch4 and D114 mRNA levels in the LPS group were increased by 3.3 and 4.6-fold, respectively. In addition, the mRNA expression levels of VEGF and its receptors Flt-1 and Flk-1 in PMVECs showed a similar increase as that of Notch4/Dll4 (all P<0.05; Fig. 3D-F). Compared with those of the control group, the mRNA expression levels of VEGF, Flt-1 and Flk-1 in the LPS group were elevated by 6.5, 6.7 and 5.3-fold, respectively. Similar results were also observed for the protein levels by western blot analysis (Fig. 3G). The present findings suggest that LPS treatment can induce the expression of Notch4, Dl14, VEGF, Flt-1 and Flk-1 in PMVECs.

Notch4/Dll4 inhibition reverses the LPS-induced upregulation of VEGF, Flt-1 and Flk-1 in PMVECs. To determine whether the Notch4/Dll4 signaling pathway is involved in the LPS-induced upregulation of angiogenic markers in PMVECs, the present study determined the levels of VEGF, Flt-1 and Flk-1 following inhibition of Notch4/Dll4 signaling. Notch4/D114 inhibition by DAPT pretreatment suppressed LPS-induced VEGF, Flt-1 and Flk-1 mRNA expression by 73,78 and $70 \%$, respectively, compared with that of the LPS group (Fig. 3D-F). Western blotting also confirmed that VEGF, Flt-1 and Flk-1 protein expression in the DAPT+LPS group was significantly decreased compared with that in the LPS group $(\mathrm{P}<0.05$; Fig. $3 \mathrm{G})$. These data demonstrate that the Notch4/Dl14 pathway may regulate LPS-induced VEGF, Flt-1 and Flk-1 expression in PMVECs. 
A

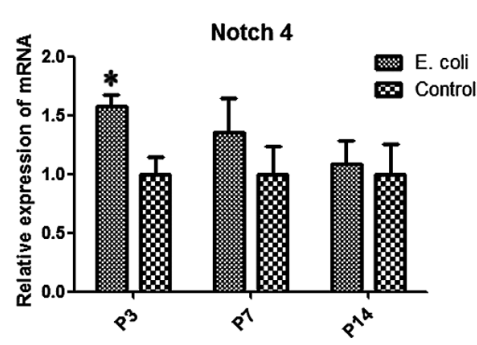

$\mathrm{D}$
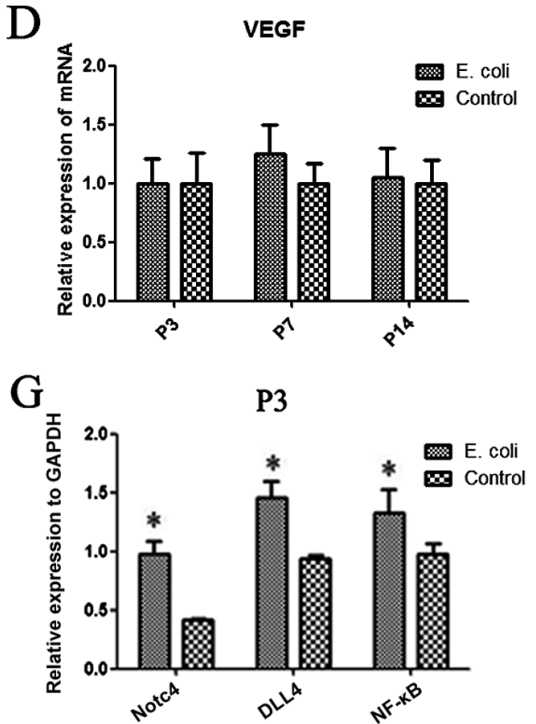

B

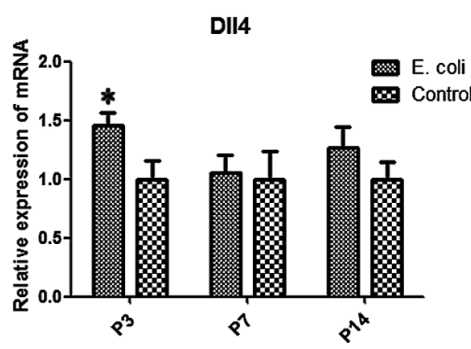

$\mathrm{E}$

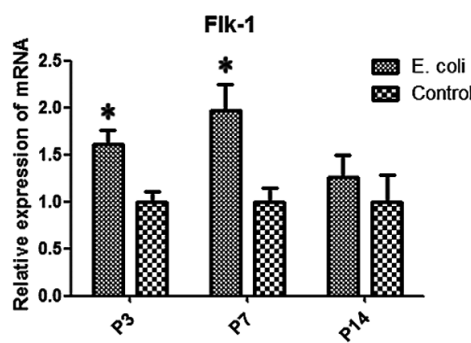

$\mathrm{C}$

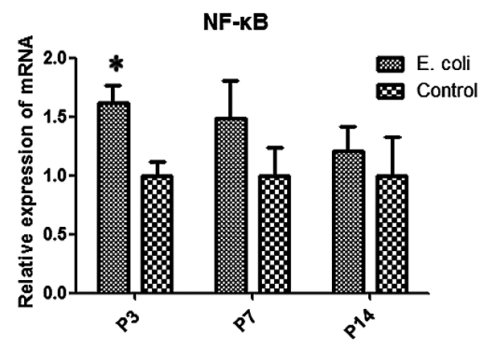

$\mathrm{F}$

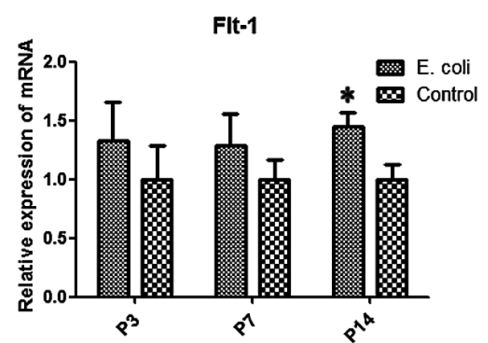

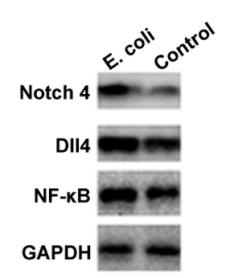

$\mathrm{H}$
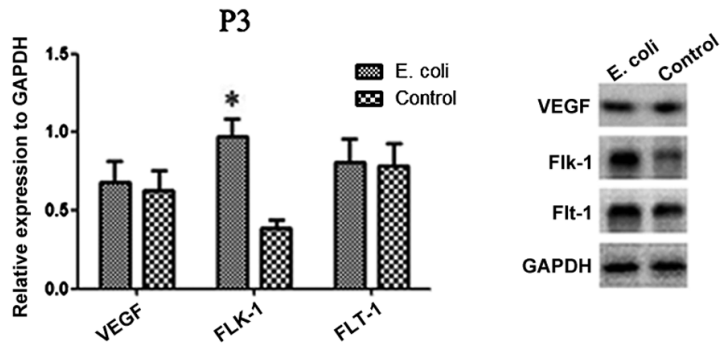

Figure 2. Aberrant expression of Notch4, Dl14, NF-kB, VEGF, Flt-1 and Flk-1 in the rat lung after intrauterine infection. (A) The mRNA expression levels of Notch4, (B) Dl14, (C) NF-kB, (D) VEGF, (E) Flk-1 and (F) Flt-1 were evaluated in the two groups by reverse transcription-quantitative PCR. (G) The protein expression levels of Notch4, Dl14 and NF-кB, and (H) VEGF, Flt-1 and Flk-1 were determined in the two groups at P3 by western blotting. Data are presented as the mean $\pm \mathrm{SD}$ ( $\mathrm{n}=10$ per group). ${ }^{*} \mathrm{P}<0.05$. Dl14, delta-like canonical Notch ligand 4; Flt-1, FMS-like tyrosine kinase 1; Flk-1, fetal liver kinase 1; P, postnatal day.

LPS-induced NF- $\mathrm{B} B$ expression is reversed by inhibiting Notch4/Dll4 in PMVECs. The promoters of VEGF, Flt-1 and Flk-1 contain binding sites for the transcription factor NF- $\mathrm{KB}$. To investigate the role of Notch4/D114 in the regulation of angiogenic gene expression in PMVECs, the present study determined the expression levels of NF- $\mathrm{KB}$ following LPS treatment. The protein expression levels of NF- $\kappa \mathrm{B}$ in the LPS group were significantly increased compared with those in the control group $(\mathrm{P}<0.05$; Fig. 4A). Of note, this upregulation was significantly suppressed by DAPT treatment (Fig. 4A). Additionally, LPS induced a 5.9-fold increase in NF- $\mathrm{B}$ mRNA levels compared with those of the control cells (Fig. 4B), while these were decreased by $67 \%$ following DAPT treatment (Fig. 4B). These data suggest that the effect of LPS on NF- $\kappa B$ expression in PMVECs may be modulated by Notch4/Dll4 signaling.

Notch4/Dll4 inhibition increases cell proliferation and decreases the apoptosis rate of LPS-stimulated PMVECs. Compared with that of the control group, LPS suppressed PMVEC proliferation (Fig. 4C). In specific, as the culture time increased, the numbers of viable cells were gradually decreased in the LPS group compared with the control group. Pretreatment with DAPT attenuated this suppression compared with the LPS alone group. The cell viability in the DAPT+LPS group was higher compared with that in the LPS group at each time point, and the differences between the two groups were significant $(\mathrm{P}<0.05$; Fig. $4 \mathrm{C})$.
Next, flow cytometry analysis revealed that the inhibition of Notch4/Dl14 signaling abrogated the LPS-induced apoptosis in PMVECs. The average apoptotic rate of PMVECs in the LPS group (exposed to LPS for $48 \mathrm{~h} ; 49.5 \%$ apoptotic cells) was significantly higher compared with that of cells in the control group (4.2\% apoptotic cells; $\mathrm{P}<0.05$ ). In the DAPT+LPS group, the average rate of apoptosis was $20 \%$, which was significantly lower compared with that of the LPS group $(\mathrm{P}<0.05$; Fig. 4D). These results indicate a key role of Notch4/D114 signaling in PMVEC proliferation and apoptosis.

\section{Discussion}

The present study revealed that intrauterine $E$. coli infection impaired alveolarization and vascular development in the rat lung, which was marked by decreased microvessel density, fewer alveoli, fewer secondary septa, and larger alveoli compared with the control group. Notch4 and Dll4 expression was significantly increased in the E. coli-infected group at P3 compared with the control group. Furthermore, the inhibition of Notch4 signaling in PMVECs contributed to decreases in LPS-induced VEGF, Flt-1, Flk-1 and NF- $\kappa B$ expression. The inhibition of Notch4/D114 signaling accelerated cell proliferation and decreased the apoptosis rate of LPS-stimulated PMVECs.

Numerous studies have demonstrated the relationship between intrauterine infection/inflammation and BPD. It has 
A

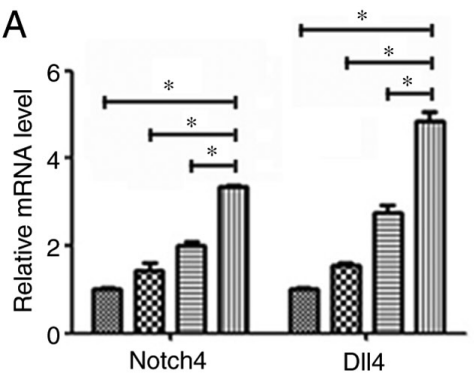

C
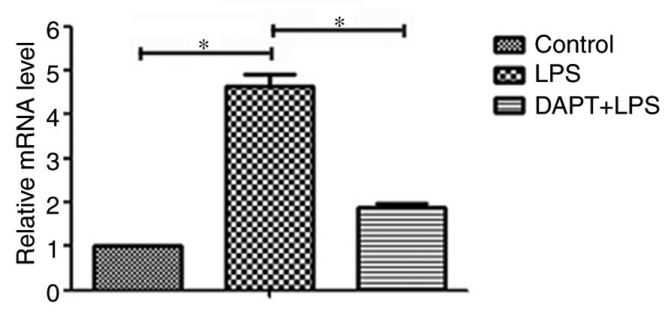

$E$
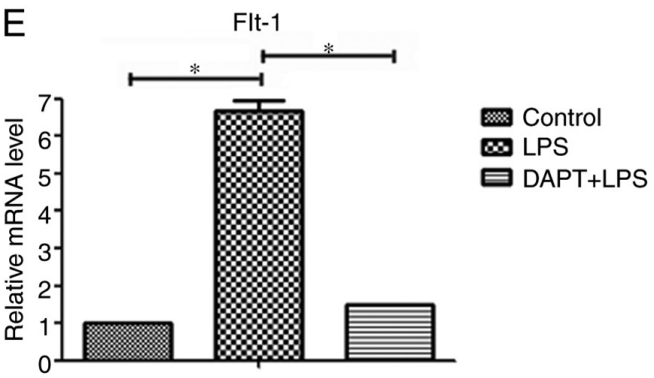

PMVECs

$\infty$ PMVECs $+0.1 \mu \mathrm{g} / \mathrm{ml}$ LPS

曰PMVECs+1 $\mu \mathrm{g} / \mathrm{ml}$ LPS

띠 PMVECs $+10 \mu \mathrm{g} / \mathrm{ml}$ LPS
B

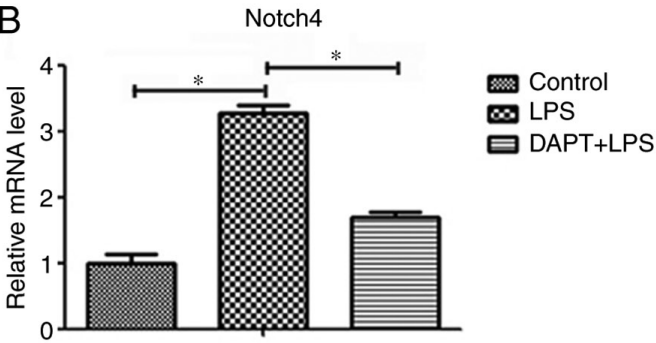

D

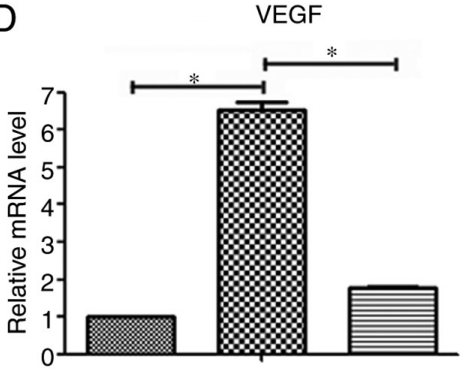

F
Contro

$\infty$ LPS

DAPT+LPS

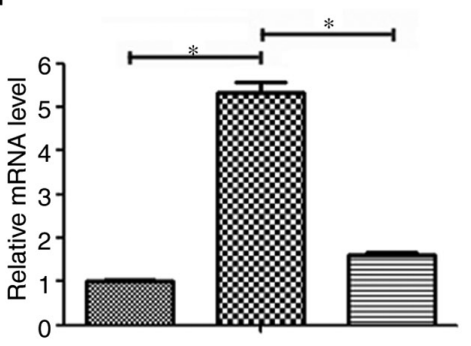

\section{G}

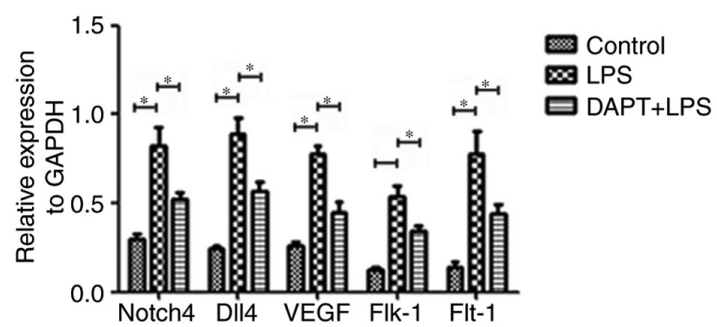

Figure 3. Inhibition of Notch4/D114 signaling decreases the expression of VEGF and its receptors in LPS-induced PMVECs. (A) The mRNA expression levels of Notch4 and Dl14 were determined by reverse transcription-quantitative PCR in PMVECs that were exposed to different concentrations of LPS. (B) Notch4, (C) Dll4, (D) VEGF, (E) Flt-1 and (F) Flk-1 mRNA levels were determined in PMVECs in the control, LPS and DAPT+LPS groups. (G) Western blot analysis of protein expression levels in the PMVEC treatment groups. Data are presented as the mean $\pm \mathrm{SD}$ ( $\mathrm{n}=6$ per group). ${ }^{*} \mathrm{P}<0.05$ with comparisons shown by lines. Dll4, delta-like canonical Notch ligand 4; PMVECs, pulmonary microvascular endothelial cells; LPS, lipopolysaccharide; Flt-1, FMS-like tyrosine kinase 1; Flk-1, fetal liver kinase 1.

become increasingly evident that intrauterine infection/inflammation impairs pulmonary vascular development in premature infants $(6,20)$. The pulmonary vasculature serves an essential role in normal lung development. Dysregulated angiogenesis during fetal growth may impair alveolarization and contribute to the development of BPD. In the present study, intrauterine infection in a rat model resulted in the arrest of pulmonary alveolarization similar to that in human BPD, and impairments in normal lung vascular development were marked by reduced microvessel density in the lung.

However, the molecular mechanisms of vascular development in BPD remain unclear. Notch receptors and their ligands have important roles in vascular development. The combined loss of Notch 4 and Notch1 in mice results in defects in vascular remodeling (21). Among the Notch family members, Notch4 and D114 are primarily expressed in vascular endothelial cells. 

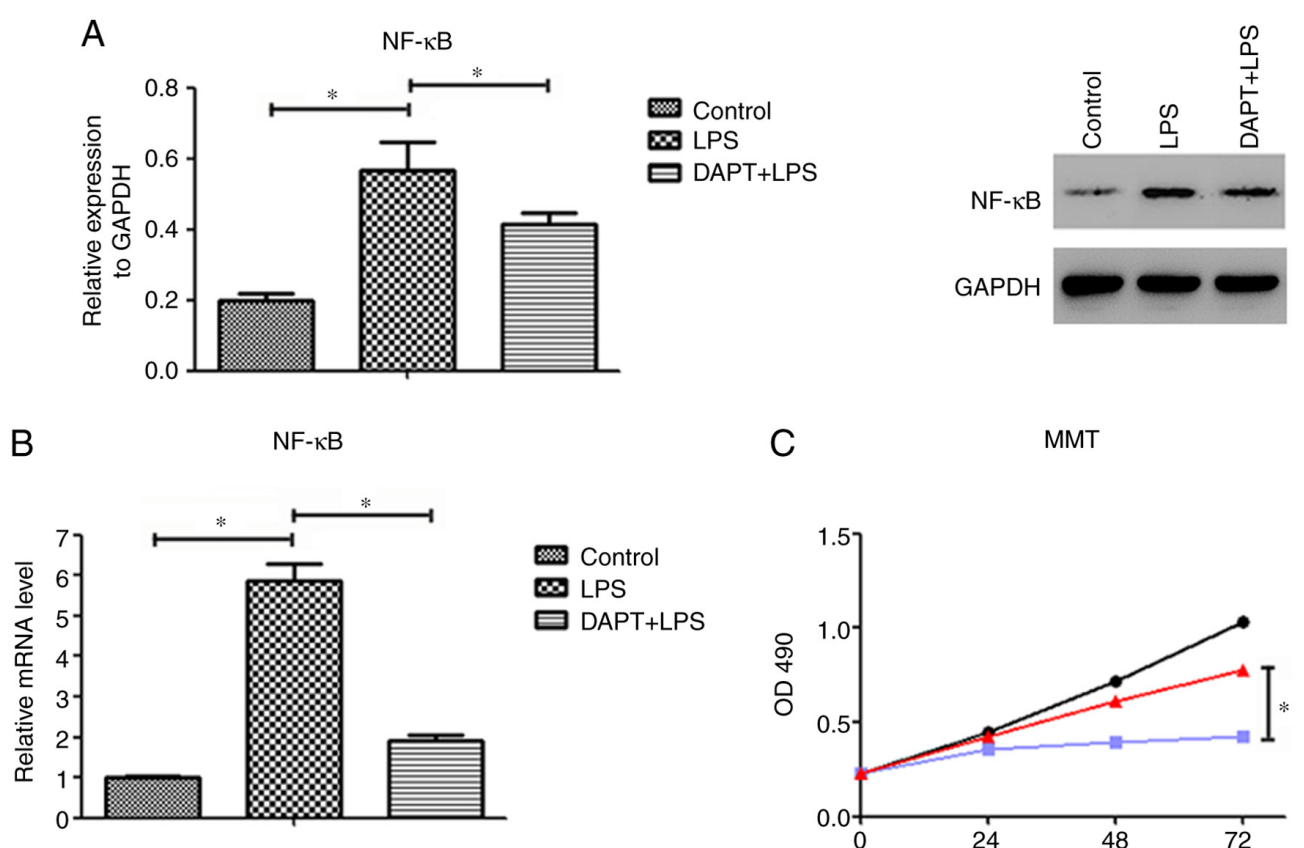

C MMT
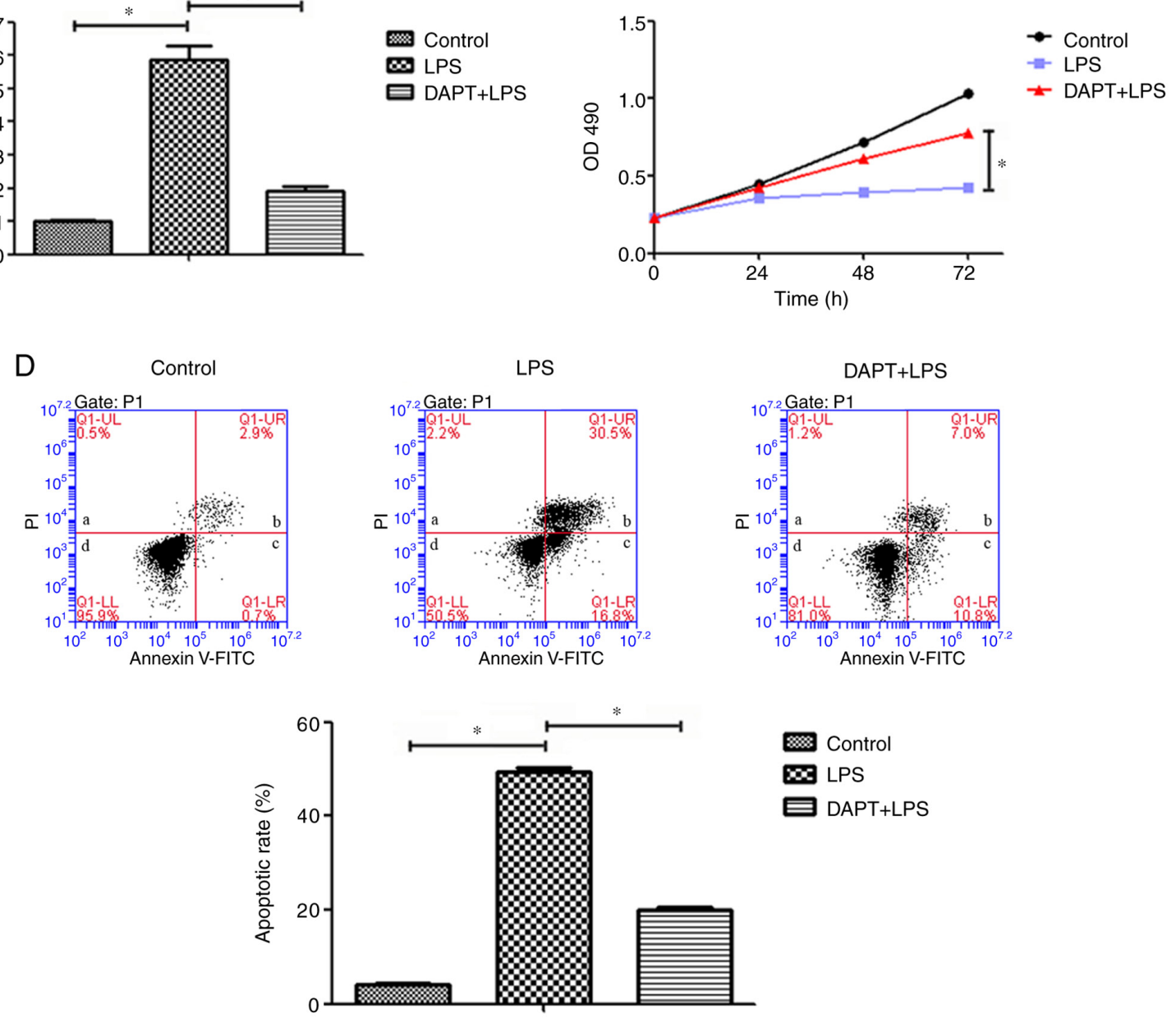

Figure 4. Inhibition of Notch4/D114 signaling decreased the expression of NF- $\mathrm{KB}$, inhibited cell apoptosis and promoted cell proliferation in PMVECs. (A) Protein and (B) mRNA expression levels of NF-kB in PMVECs in the control, LPS and DAPT+LPS groups. (C) Cell viability in the control, LPS and DAPT+LPS groups was measured using an MTT assay. (D) Representative plots and quantitative flow cytometric analysis of the apoptotic rates of PMVECs in the control, LPS and DAPT+LPS groups. In the plots, quadrant a shows the proportion of dead/necrotic cells (Annexin V-FITC $/ \mathrm{PI}^{+}$), quadrant $b$ shows the late apoptotic cells (Annexin V-FITC $/ \mathrm{PI}^{+}$), quadrant c shows the early apoptotic cells (Annexin $\mathrm{V}-\mathrm{FITC}^{+} / \mathrm{PI}^{-}$) and quadrant $\mathrm{d}$ shows the live cells (Annexin V-FITC $/ \mathrm{PI}$ ). The sum of quadrants $\mathrm{b}$ and $\mathrm{c}$ was calculated as the apoptotic rate. Data are presented as the mean $\pm \mathrm{SD}\left(\mathrm{n}=6 \mathrm{per}\right.$ group). ${ }^{*} \mathrm{P}<0.05$ with comparisons shown by lines. Dl14, delta-like canonical Notch ligand 4; PMVECs, pulmonary microvascular endothelial cells; LPS, lipopolysaccharide; PI, propidium iodide.

The overexpression of activated Notch4 results in vascular patterning defects (22), while D1l4 haploinsufficiency induces major defects in vascular development, resulting in embryonic lethality $(23,24)$. Qiao et al $(25)$ also showed that inhibiting Notch signaling with a $\gamma$-secretase inhibitor protected against angiotensin II-induced pulmonary vascular remodeling. These findings emphasize the critical role of Notch4/D114 in vascular development. Notably, the present results demonstrated that Notch4 and D114 expression was significantly increased in the $E$. coli-infected group at P3. In vitro, Notch4/D114 mRNA expression levels in LPS-stimulated PMVECs were also significantly higher compared with those in the controls. These data reveal that Notch4/Dll4 signaling may be critically involved in intrauterine infection-induced impairments in lung development.

VEGF and VEGFR have key roles in stimulating angiogenesis and vasculogenesis $(26,27)$. The appropriate expression of VEGF not only contributes to the formation of capillaries but 
also controls alveolar and bronchial growth (28). Changes in VEGF and its receptors result in angiogenesis disorders, which contribute to detrimental remodeling of small arteries (7). In the current study, there was a significant difference in the Flk-1 mRNA levels at P3 and P7 between the two groups, while the mRNA expression levels of Flt-1 were significantly increased at P14 compared with those of the control group. The present data demonstrated that intrauterine infection disturbed VEGF signaling. Furthermore, inhibiting Notch4/D114 signaling decreased apoptosis, promoted cell proliferation, and decreased the expression of VEGF and its receptors Flk-1 and Flt-1 in LPS-induced PMVECs. These results indicate that Notch4/D114 and VEGF signaling may be associated with intrauterine infection-induced BPD.

Currently, the role of Notch4/Dll4 signaling in the process of BPD is not well understood. To explore the molecularmechanisms underlying Notch4-mediated regulation of lung development, the present study evaluated the expression of NF- $\kappa \mathrm{B}$. As a pivotal regulator of inflammation, the $\mathrm{NF}-\kappa \mathrm{B}$ pathway has been shown to promote lung injury in many models (29). In addition, it was observed that the activation of $\mathrm{NF}-\kappa \mathrm{B}$ promoted alveolarization and pulmonary angiogenesis (29). Alvira (30) suggested that NF- $\mathrm{KB}$ might play an essential, unique and beneficial role in lung development. In the present study, LPS induced a large increase in $\mathrm{NF}-\kappa \mathrm{B}$ expression in PMVECs compared with that of the control cells. Furthermore, the inhibition of Notch4 signaling by a $\gamma$-secretase inhibitor significantly decreased NF- $\kappa \mathrm{B}$ expression in PMVECs compared with that of the LPS group. Taken together, these results demonstrated that Notch4/Dll4 signaling may have an important role in the development of BPD induced by intrauterine infection, possibly through the NF- $\kappa \mathrm{B}$ pathway and downstream target genes, such as VEGF, Flk-1 and Flt-1. However, the present study has certain limitations, such as the lack of Notch4 knockout or overexpression experiments, which would further clarify the effect of Notch4/Dl14 on lung development.

In conclusion, the current study demonstrated that early gestational intrauterine infection arrested alveolarization and vascular development in the lung and disrupted Notch4/D114 signaling. Furthermore, Notch4/D114 signaling may have an important role in lung development by regulating the expression of VEGF, Flk-1 and Flt-1. Thus, targeting the Notch4/Dll4 pathway might provide a novel therapeutic strategy for the treatment of BPD in the future.

\section{Acknowledgements}

Not applicable.

\section{Funding}

This work was financially supported by the National Natural Science Foundation of China (grant no. 81401235; recipient, Canyang Zhan).

\section{Availability of data and materials}

The datasets used and/or analyzed during the current study are available from the corresponding author on reasonable request.

\section{Authors' contributions}

CZ and LC conceived and designed the study, collected and analyzed the data and wrote the manuscript. CZ, YS and JP performed experiments. YS performed the data analysis and interpretation. TY designed the study, analyzed the data and supervised the entire project. CZ and YS confirm the authenticity of the raw data. All authors read and approved the final manuscript.

\section{Ethics approval and consent to participate}

All animal procedures and protocols were reviewed and approved by the Animal Care Committee of Zhejiang University (Hangzhou, China).

\section{Patient consent for publication}

Not applicable.

\section{Competing interests}

The authors declare that they have no competing interests.

\section{References}

1. Zysman-Colman Z, Tremblay GM, Bandeali S and Landry JS: Bronchopulmonary dysplasia-trends over three decades. Paediatr Child Health 18: 86-90, 2013.

2. Jobe AH: What is BPD in 2012 and what will BPD become? Early Hum Dev 88: S27-S28, 2012.

3. Thébaud B and Abman SH: Bronchopulmonary dysplasia: Where have all the vessels gone? Roles of angiogenic growth factors in chronic lung disease. Am J Respir Crit Care Med 175: 978-985, 2007.

4. De Paepe ME, Greco D and Mao Q: Angiogenesis-related gene expression profiling in ventilated preterm human lungs. Exp Lung Res 36: 399-410, 2010.

5. Stenmark KR and Abman SH: Lung vascular development: Implications for the pathogenesis of bronchopulmonary dysplasia. Annu Rev Physiol 67: 623-661, 2005.

6. Hartling L, Liang Y and Lacaze-Masmonteil T: Chorioamnionitis as a risk factor for bronchopulmonary dysplasia: A systematic review and meta-analysis. Arch Dis Child Fetal Neonatal Ed 97: F8-F17, 2012.

7. Cao L, Wang J, Tseu I, Luo D and Post M: Maternal exposure to endotoxin delays alveolarization during postnatal rat lung development. Am J Physiol Lung Cell Mol Physiol 296: L726-L737, 2009.

8. Kim DH, Choi CW, Kim EK, Kim HS, Kim BI, Choi JH, Lee MJ and Yang EG: Association of increased pulmonary interleukin-6 with the priming effect of intra-amniotic lipopolysaccharide on hyperoxic lung injury in a rat model of bronchopulmonary dysplasia. Neonatology 98: 23-32, 2010.

9. Kume T: Ligand-Dependent notch signaling in vascular formation. Adv Exp Med Biol 727: 210-222, 2012.

10. Hori K, Sen A and Artavanis-Tsakonas S: Notch signaling at a glance. J Cell Sci 126: 2135-2140, 2013.

11. Caolo V, Molin DG and Post MJ: Notch regulation of hematopoiesis, endothelial precursor cells, and blood vessel formation: Orchestrating the vasculature. Stem Cells Int 2012: 805602, 2012.

12. Zhan CY, Yuan TM, Sun Y and Yu HM: Early gestational intrauterine infection induces postnatal lung inflammation and arrests lung development in a rat model. J Matern Fetal Neonatal Med 24: 213-222, 2011.

13. Pan J, Zhan C, Yuan T, Wang W, Shen Y, Sun Y, Wu T, Gu W, Chen L and Yu H: Effects and molecular mechanisms of intrauterine infection/inflammation on lung development. Respir Res 19: 93, 2018.

14. Uenishi GI, Jung HS, Kumar A, Park MA, Hadland BK, McLeod E, Raymond M, Moskvin O, Zimmerman CE, Theisen DJ, et al: NOTCH signaling specifies arterial-type definitive hemogenic endotheliumfrom human pluripotent stem cells. Nat Commun 9: 1828, 2018. 
15. Zhao H, Xu CN, Huang C, Jiang J and Li L: Notch1 signaling participates in the release of inflammatory mediators in mouse RAW264.7 cells via activating NF- $\mathrm{B}$ pathway. Xi Bao Yu Fen Zi Mian Yi Xue Za Zhi 33: 1310-1315, 2017 (In Chinese).

16. Wang Y, Chen H, Li H, Zhang J and Gao Y: Effect of angiopoietin-like protein 4 on rat pulmonary microvascular endothelial cells exposed to LPS. Int J Mol Med 32: 568-576, 2013.

17. Zhou HS, Li M, Sui BD, Wei L, Hou R, Chen WS, Li Q, Bi SH, Zhang JZ and Yi DH: Lipopolysaccharide impairs permeability of pulmonary microvascular endothelial cells via connexin 40 Microvasc Res 115: 58-67, 2018.

18. Zhang K, Wang P, Huang S, Wang X, Li T, Jin Y, Hehir M and Xu C: Different mechanism of LPS-induced calcium increase in human lung epithelial cell and microvascular endothelial cell: A cell culture study in a model for ARDS. Mol Biol Rep 41: 4253-4259, 2014.

19. Livak KJ and Schmittgen TD: Analysis of relative gene expression data using real-time quantitative PCR and the 2(-Delta Delta C(T)) method. Methods 25: 402-408, 2001

20. Landry JS, Chan T, Lands L and Menzies D: Long-Term impact of bronchopulmonary dysplasia on pulmonary function. Can Respir J 18: 265-270, 2011.

21. Krebs LT, Xue Y, Norton CR, Shutter JR, Maguire M, Sundberg JP, Gallahan D, Closson V, Kitajewski J, Callahan R, et al: Notch signaling is essential for vascular morphogenesis in mice. Genes Dev 14: 1343-1352, 2000

22. Uyttendaele H, Ho J, Rossant J and Kitajewski J: Vascular patterning defects associated with expression of activated notch4 in embryonic endothelium. Proc Natl Acad Sci USA 98: 5643-5648, 2001.

23. Gale NW, Dominguez MG, Noguera I, Pan L, Hughes V, Valenzuela DM, Murphy AJ, Adams NC, Lin HC, Holash J, et al: Haploinsufficiency of delta-like 4 ligand results in embryonic lethality due to major defects in arterial and vascular development. Proc Natl Acad Sci USA 101: 15949-15954, 2004.
24. Trindade A, Kumar SR, Scehnet JS, Lopes-da-Costa L, Becker J, Jiang W, Liu R, Gill PS and Duarte A: Overexpression of delta-like 4 induces arterialization and attenuates vessel formation in developing mouse embryos. Blood 112: 1720-1729, 2008.

25. Qiao LN, Xu HB, Shi K, Zhou TF, Hua YM and Liu HM: Role of notch signal in angiotensin II induced pulmonary vascular remodeling. Transl Pediatr 2: 5-13, 2013.

26. Muratore CS, Luks FI, Zhou Y, Harty M, Reichner J and Tracy TF: Endotoxin alters early fetal lung morphogenesis. J Surg Res 155: 225-230, 2009.

27. Kallapur SG, Bachurski CJ, Le Cras TD, Joshi SN, Ikegami M and Jobe AH: Vascular changes after intra-amniotic endotoxin in preterm lamb lungs. Am J Physiol Lung Cell Mol Physiol 287: L1178-L1185, 2004.

28. Bhatt AJ, Pryhuber GS, Huyck H, Watkins RH, Metlay LA and Maniscalco WM: Disrupted pulmonary vasculature and decreased vascular endothelial growth factor, Flt-1, and TIE-2 in human infants dying with bronchopulmonary dysplasia. Am J Respir Crit Care Med 164: 1971-1980, 2001.

29. Hou Y, Liu M, Husted C, Chen C, Thiagarajan K, Johns JL, Rao SP and Alvira CM: Activation of the nuclear factor $-\kappa \mathrm{B}$ pathway during postnatal lung inflammation preserves alveolarization by suppressing macrophage inflammatory protein-2. Am J Physiol Lung Cell Mol Physiol 309: L593-L604, 2015.

30. Alvira CM: Nuclear factor-kappa-B signaling in lung development and disease: One pathway, numerousfunctions. Birth Defects Res A Clin Mol Teratol 100: 202-216, 2014.

This work is licensed under a Creative Commons Attribution-NonCommercial-NoDerivatives 4.0 International (CC BY-NC-ND 4.0) License. 